\title{
A Comparative Study of Whole-Mouth Taste Thresholds between North Korean Refugees and South Koreans
}

\author{
Eun-Young Kim ${ }^{1 *}$, Yiseul Kim ${ }^{1 *}$, Youngjoo Lee ${ }^{2}$, and Mee-Ra Rhyu ${ }^{1}$ \\ ${ }^{I}$ Division of Functional Food Research, Korea Food Research Institute, Wanju; and \\ ${ }^{2}$ Department of Integrative Bioscience and Biotechnology, College of Life Science, Sejong University, Seoul, Korea
}

\section{북한 이탈주민과 남한 주민과의 미각 역치 비교 연구}

김은영 ${ }^{*} \cdot$ 김이슬 $^{*} \cdot$ 이영주 $^{2} \cdot$ 류미라 $^{1}$

한국식품연구원, ${ }^{1}$ 세종대학교 바이오융합공학과 ${ }^{2}$

\author{
Received March 5, 2019 \\ Revised July 12, 2019 \\ Accepted August 1, 2019 \\ Address for correspondence \\ Mee-Ra Rhyu, PhD \\ Division of Functional \\ Food Research, Korea Food \\ Research Institute, \\ 245 Nongsaengmyeong-ro, \\ Iseo-myeon, Wanju 55365, Korea \\ Tel $+82-63-219-9268$ \\ Fax $+82-63-219-9876$ \\ E-mail mrrhyu@kfri.re.kr \\ *These authors contributed equaly \\ tothis work.
}

Background and Objectives Since Korea has been divided into two countries over 60 years ago and differences has gradually developed between the two, an influx of North Korean refugees to South Korea have soared over the past 20 years. Their complaints regarding taste intensity, particularly about strong sweetness of foods, are common after entry into South Korea. Because a long-term over-exposure or restriction to some taste stimuli causes profound alterations in corresponding taste sensitivity in humans, we hypothesized that sugar restriction, which remains common in North Korea, has influenced sweet sensitivity of North Koreans.

Subjects and Method To test this hypothesis, we assessed the taste stimuli recognition and detection thresholds of both young adults North refugees and South Koreans using a 1-mL whole-mouth gustatory test applied to a series of sweet, bitter, sour, and salty solutions.

Results As expected, the cumulative curve of the recognition threshold for sucrose shifted to the left and the mean recognition threshold for sucrose was significantly lower $(0.5357 \% \mathrm{vs}$. $0.7393 \%, p=0.044$ ) for North refugees than for South participants. On the other hand, the recognition threshold for salt was significantly higher $(0.2174 \%$ vs. $0.1212 \%, p=0.027)$ in North refugees. No differences on the recognition taste sensitivity for quinine hydrochloride and citric acid were observed.

Conclusion The findings documented in the present study indicate that a prolonged food deficit seems to have changed the taste sensitivity of healthy North Korean refugees. The altered taste sensitivity was most pronounced for sweet and salty tastes, and lasted up to 3.5 years after the refugees left North Korea.

Korean J Otorhinolaryngol-Head Neck Surg 2019;62(11):631-6

Key Words Refugees · Taste perception · Taste threshold.

\section{Introduction}

Since Korea was divided into two countries over 60 years ago, differences have gradually developed at the political and economic levels. Because North Koreans have faced

This is an Open Access article distributed under the terms of the Creative Commons Attribution Non-Commercial License (https://creativecommons.org/licenses/by-nc/4.0) which permits unrestricted non-commercial use, distribution, and reproduction in any medium, provided the original work is properly cited. food shortages since the early 1990s, ${ }^{1)}$ the number of North Korean refugees arriving in South Korea has soared, with more than 30000 settling in South Korea. ${ }^{2)}$ North Korean refugees stay at Hanawon, a settlement support center, during their first 3 months after entry into South Korea. Their complaints regarding taste intensity, particularly with respect to strong sweetness, of prepared or processed foods at Hanawon are common, and they persist even after the refu- 
gees have lived in South Korea for several years. ${ }^{3)}$

North Korea is designated as a low-income food-deficit country based on the per capita gross national income and net food trade status by the Food and Agriculture Organization. ${ }^{4}$ Sugar restrictions and spice resource limitations remain common in North Korea. Because long-term over-exposure to sweet, salty, or sour taste stimuli, mostly caused by sociological factors within a country, it causes profound alterations in corresponding taste sensitivity in humans. ${ }^{5-7)}$ It is plausible that limited exposure to sweet stimuli or over-exposure to salt would alter taste sensitivity in North Koreans.

We therefore hypothesized that a long-term over-exposure or restriction to some taste stimuli within a country caused by food deficit has influenced the taste sensitivity of young adult North Korean refugees. To test this hypothesis, we assessed the taste stimuli detection and recognition thresholds of both young adult North Korean refugees and South Koreans using a 1-mL whole-mouth gustatory test applied to a series of sweet, bitter, sour, and salty solutions.

\section{Subjects and method}

\section{Participant recruitment}

This study recruited 23 North Korean refugees from a religious facility in Guro-gu, Seoul. The participants were aged between 18 years and 34 years old and provided informed consent before the assessments. The study protocol was approved by the Institutional Review Board (IRB SJU-HR-E-2019-008) of Sejong University, Seoul, Korea. We measured the height and weight of the subjects, and obtained information on their age, cigarette smoking habits, and consumption of alcoholic beverages. During face-to-face interviews, we asked the North Korean refugees for the date of their escape from North Korea, the date of their arrival in South Korea, and the number of months they spent in transit between the two countries (i.e., in China) to calculate the length of their residence in South Korea. Heavy smokers ( $\geq 20$ cigarettes per day) and heavy alcohol consumers ( $\geq 5$ drinks of alcohol per day; one drink is equivalent to $12 \mathrm{~g}$ of alcohol) were excluded from the analysis because these substances can modify taste perception. ${ }^{8)}$ We also excluded those who could not distinguish between distilled water and the sample solutions. Ultimately, 21 young adult North Korean refugees (12 men, 9 women) participated.

In total, 72 young adult South Koreans (40 men, 32 women; age range: $18-26$ years) were recruited from universities in the metropolitan area of South Korea; they all provided informed consent before participating. The subjects were asked the same questions as the North Korean refugees, and the exclusion criteria were identical. Finally, 41 South Korean young adults (20 men, 21 women) were included in the analysis. Table 1 summarizes the general characteristics of the participants.

\section{Test solutions}

To determine the taste stimuli detection and recognition thresholds, we prepared a series of solutions corresponding to the four basic tastes (sweet, salty, sour, and bitter) using sucrose, sodium chloride $(\mathrm{NaCl})$, citric acid, and quinine hydrochloride $(\mathrm{QHCl})$, respectively. The concentration range for each test compound was chosen based on the reported threshold values. The highest-concentration solutions were $40 \%$ sucrose, $20 \% \mathrm{NaCl}, 2 \%$ citric acid, and $0.1 \% \mathrm{QHCl}$. Solutions with lower concentrations were obtained by serial dilution with distilled water (ratio of 1:1), as shown in Table 2. All test solutions were stored at $4^{\circ} \mathrm{C}$ until use.

\section{Measurement of taste thresholds}

To ensure the accuracy of the threshold tests, the subjects were instructed to refrain from eating a meal, drinking (except water), smoking, or chewing gum for at least $1 \mathrm{~h}$ before the start of the test. Before the test, the subjects rinsed out their mouths with distilled water; then $1 \mathrm{~mL}$ of each stepwise test solution was sprayed evenly over the subject's tongue surface using a disposable syringe. The subjects retained each solution in their mouths for a short period and then spat it out. Each

Table 1. General characteristics of participants

\begin{tabular}{lccc}
\hline \multicolumn{1}{c}{ Characteristic } & $\begin{array}{c}\text { North Korean } \\
\text { refugees } \\
(\mathrm{n}=21)\end{array}$ & $\begin{array}{c}\text { South } \\
\text { Koreans } \\
(\mathrm{n}=41)\end{array}$ & p-value* \\
\hline Age $(\mathrm{yr})$ & $24.0 \pm 0.7^{\dagger}$ & $22.1 \pm 0.4$ & 0.012 \\
Gender $(\mathrm{n})$ & 12 & 20 & \\
$\quad$ Male & 9 & 21 & 0.533 \\
$\quad$ Female & $22.7 \pm 0.5$ & $22.5 \pm 0.5$ & 0.802 \\
Body Mass Index $\left(\mathrm{kg} / \mathrm{m}^{2}\right)$ & $5.21 \pm 1.79$ & $9.25 \pm 1.11$ & 0.070 \\
Cigarette smoking & & & \\
$\quad$ (ea/day) & $1.43 \pm 0.23$ & $1.57 \pm 0.22$ & 0.770 \\
Alcohol consumption & & & \\
$\quad$ (drink/day) & & & \\
Residential period (yr) & & & \\
$\quad$ North Korea & $20.8 \pm 0.6$ & & \\
$\quad$ South Korea & $1.5 \pm 0.3$ & & \\
Stateless period (yr) & $2.0 \pm 0.7$ & &
\end{tabular}

*derived by between-groups comparisons by chi-square test (gender) and t test (other variables), tmean \pm standard error (all such values), $\neq$ one drink of alcohol= $12 \mathrm{~g}$ of ethanol 
Table 2. Concentrations of solution used for whole-mouth gustatory test

\begin{tabular}{crrrr}
\hline Concentration & $\begin{array}{c}\text { Sucrose } \\
(\%)\end{array}$ & \multicolumn{1}{c}{$\begin{array}{c}\mathrm{NaCl} \\
(\%)\end{array}$} & $\begin{array}{c}\text { Citric acid } \\
(\%)\end{array}$ & \multicolumn{1}{c}{$\begin{array}{c}\mathrm{QHCl} \\
(\%)\end{array}$} \\
\hline C1 & 0.00977 & 0.00488 & 0.00048 & 0.00002 \\
C2 & 0.0195 & 0.00977 & 0.00098 & 0.00005 \\
C3 & 0.0391 & 0.0195 & 0.00195 & 0.00010 \\
C4 & 0.0781 & 0.0391 & 0.00391 & 0.00020 \\
C5 & 0.1563 & 0.0781 & 0.00781 & 0.00039 \\
C6 & 0.313 & 0.1563 & 0.01563 & 0.00078 \\
C7 & 0.625 & 0.313 & 0.0313 & 0.00156 \\
C8 & 1.25 & 0.625 & 0.0625 & 0.00313 \\
C9 & 2.5 & 1.25 & 0.125 & 0.00625 \\
C10 & 5.0 & 2.5 & 0.25 & 0.0125 \\
C11 & 10.0 & 5.0 & 0.5 & 0.025 \\
C12 & 20.0 & 10.0 & 1.0 & 0.050 \\
C13 & 40.0 & 20.0 & 2.0 & 0.10 \\
\hline
\end{tabular}

subject was asked first to discriminate between the taste of the test solution and the previous solution, and then to identify the taste of the test solution. The minimum concentrations at which the subjects could discriminate the test solutions from distilled water, and identify the taste correctly, were defined as the detection and recognition thresholds, respectively. When subjects switched from one test solution to another, they first rinsed out their mouths with distilled water. However, when the concentration of the same test solution was increased, they did not rinse their mouths, except in the case of the salty taste.

\section{Data analysis}

Data are presented as means \pm standard error of the mean. Statistical significance of difference was analyzed by chisquare test on gender and one-tailed Student's t-test on other variables. Significant differences were accepted when the $p$ value was $<0.05$.

\section{Results}

\section{The recognition threshold for bitter, sour, sweet, and salty tastes in North and South Korean young adult participants}

Two different gustatory thresholds are often used to assess taste sensitivity in humans: the recognition and detection thresholds. The detection threshold is defined as the minimum concentration of a taste chemical that can be reliably discriminated from water, although the specific taste is not necessarily recognized. The recognition threshold is defined as the minimum concentration at which a subject can accu- rately identify the type of taste, such as "sweet" for sucrose or "salty" for $\mathrm{NaCl}^{9,10)}$

Fig. 1 shows the cumulative curves of the recognition thresholds and mean recognition thresholds for the sweet, bitter, sour, and salty stimuli in our young adult North Korean refugees and South Korean participants. In the cumulative curves of the recognition threshold, the onset of the curve corresponds to the lowest threshold and the curve is plotted up to the highest threshold; the steepness of the slope is inversely related to the range width of threshold for each group. As shown in Fig. 1A, the onset, end point, and steepness of the cumulative curves of the recognition threshold for $\mathrm{QHCl}$ were quite similar between the North Korean refugees and the South Koreans. No difference was observed in mean recognition threshold between the two groups (1.0024 mg\% vs. $0.9359 \mathrm{mg} \%, p=0.394$ ). Regarding the sensitivity to citric acid, both the cumulative curve of the recognition threshold and the mean recognition threshold $(0.0201 \%$ vs. $0.0189 \%, p=0.382)$ showed no differences between the groups (Fig. 1B). These data might suggest that a sociological factor such as a prolonged food deficit does not strongly influence the recognition thresholds for bitterness and sourness in North Korean refugees. On the other hand, different sucrose sensitivity trends were found between the two groups (Fig. 1C). As expected, the cumulative curve of the recognition threshold for sucrose shifted to the left for the North Korean refugees compared with the South Korean participants. The mean recognition threshold for sucrose was also significantly lower in the North Korean refugees $(0.5357 \%$ vs. $0.7393 \%$, $p=0.044$ ), indicating that sucrose sensitivity is greater in North Korean refugees than in South Korean participants. Similarly, we found a difference in taste sensitivity between the groups for $\mathrm{NaCl}$ in terms of both the cumulative curve of the recognition threshold and mean recognition threshold (Fig. 1D). The cumulative curve of the recognition threshold among the North Korean refugees shifted to the left for $\mathrm{NaCl}$ concentrations $<0.03906 \%$ and to the right for $\mathrm{NaCl}$ concentrations $>0.03906 \%$ compared with the South Korean participants. The mean recognition threshold of the North Korean refugees was significantly higher than that of the South Korean participants $(0.2174 \%$ vs. $0.1212 \%, p=0.027$ ), indicating that sensitivity to $\mathrm{NaCl}$ was lower in the North Korean refugees than in South Korean participants.

\section{The detection threshold in North and South Korean young adult participants}

Fig. 2 shows the cumulative curves of detection thresholds 

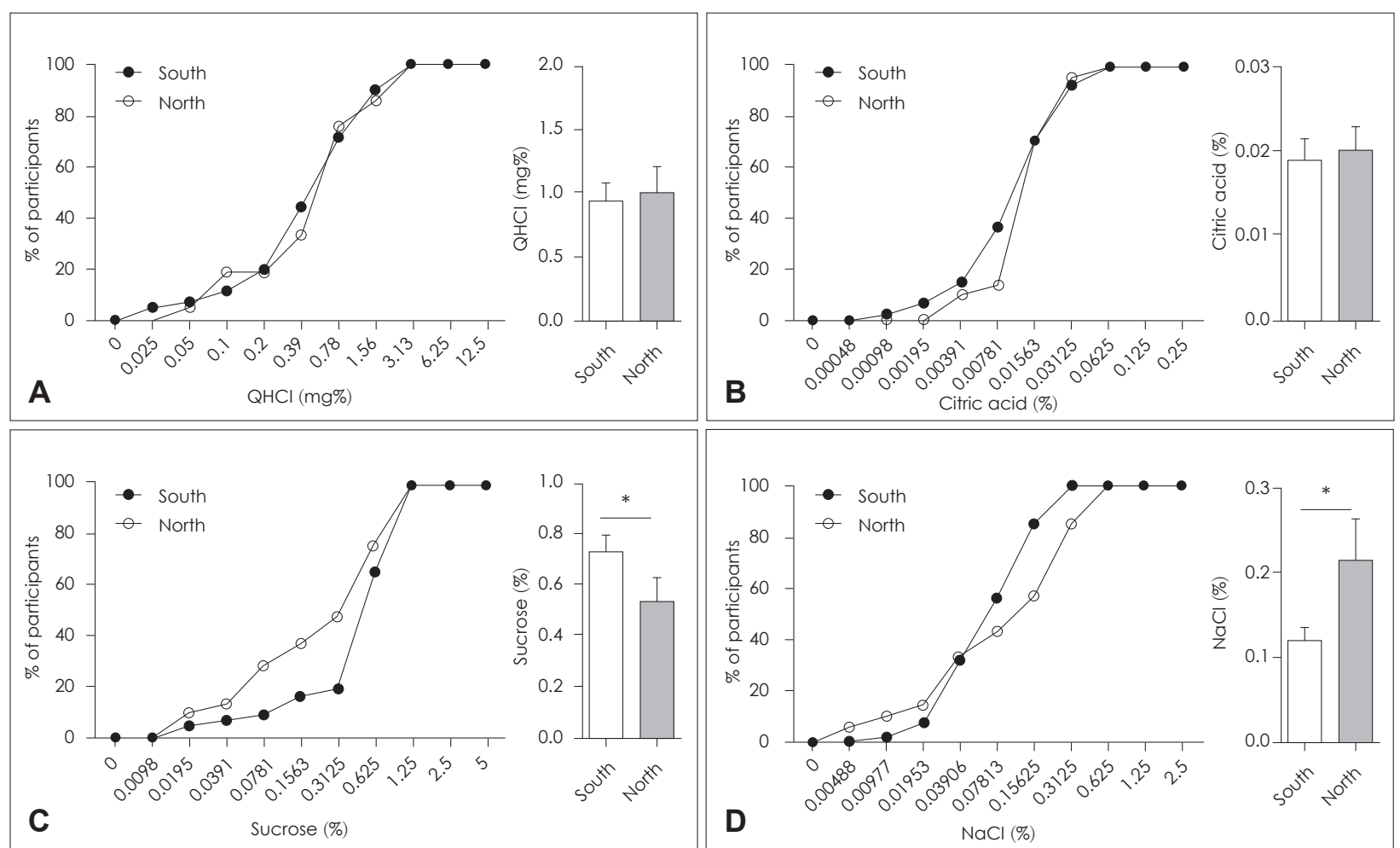

Fig. 1. The cumulative recognition threshold curves of $\mathrm{QHCl}(A)$, citric acid $(B)$, sucrose $(C)$, and $\mathrm{NaCl}(D)$ representing bitter, sour, sweet, and salty tastes, respectively. The mean recognition threshold of $\mathrm{QHCl}(\mathrm{A})$, citric acid (B), sucrose (C), and $\mathrm{NaCl}(\mathrm{D})$, respectively, in North Korean young adult refugees $(\circ, \mathrm{n}=21)$ and South Korean participants $(\bullet, \mathrm{n}=41) .{ }^{*} p<0.05$ (Student's t-test).

and mean detection thresholds for the sweet, bitter, sour, and salty stimuli for the two groups. As with the recognition threshold, the onset of the curve corresponds to the lowest threshold, and the curve is plotted up to the highest threshold; the steepness of the slope is inversely related to the threshold range width for each group. Unlike recognition thresholds, increasing the concentration of all taste stimuli tested produced a rightward shift of the cumulative curves of detection thresholds among the North Korean refugees. The mean detection thresholds for sweet $(0.2400 \%$ vs. $0.4059 \%, p=0.038)$, salty ( $0.0188 \%$ vs. $0.0373 \%, p=0.002)$, sour $(0.0030 \%$ vs. $0.0100 \%$, $p=0.001$ ), and bitter ( $0.1171 \mathrm{mg} \%$ vs. $0.4595 \mathrm{mg} \%, p=0.0005$ ) tastes were significantly lower in North Korean refugees than in South Korean participants, indicating that the overall sensitivity of detection to taste stimuli was higher in North Korean refugees than in South Korean participants.

\section{Discussion}

Although the sample size was small, the present study demonstrated that North Korean refugees' sucrose recognition threshold was significantly higher, whereas their salt rec- ognition threshold was significantly lower, compared with the recognition thresholds of South Korean participants. No dietary effect on the recognition thresholds for $\mathrm{QHCl}$ and citric acid was observed. Because sugar restriction is an unavoidable aspect of a prolonged food deficit such as that in North Korea, the data for sucrose obtained in this study are in general agreement with data previously collected by Wise et al., ${ }^{11)}$ who found that a substantial reduction in the dietary intake of sugar increased the sensitivity to sugar taste after only 1 month of reduced dietary intake. Accumulating evidence indicates that salt exposure (both restriction and hyperingestion) significantly alters salt taste sensitivity. ${ }^{12-14)}$ Although our results show no difference in sensitivity depending on the length of residence in the Republic of Korea after defecting from the North (data not shown), it is assumed that this is a problem with small sample size. Cultural factors can contribute to intake patterns and consequently influence taste sensitivity, as shown in a previous report suggesting that prolonged hyperingestion of dietary salt originated from the extensive use of salted fish products; this tradition has decreased the salt taste sensitivity of Myanmarese people. ${ }^{7)}$ Based on a report on the status of the vegetable industry in North Korea, excessive dietary salt in- 

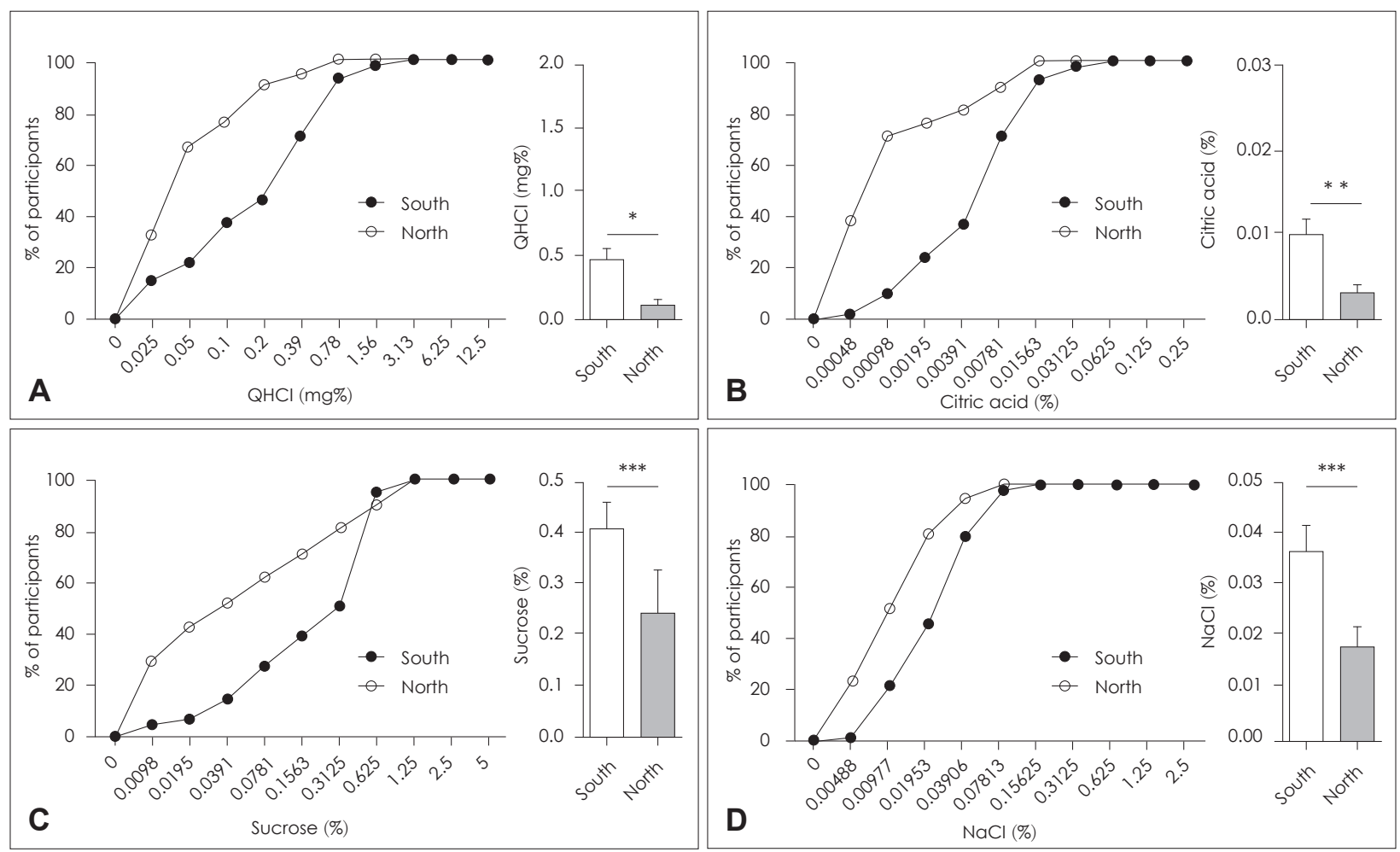

Fig. 2. The cumulative detection curves of $\mathrm{QHCl}(\mathrm{A})$, citric acid (B), sucrose (C), and $\mathrm{NaCl}(\mathrm{D})$ representing bitter, sour, sweet, and salty tastes, respectively. The mean detection threshold of $\mathrm{QHCl}(\mathrm{A})$, citric acid (B), sucrose (C), and $\mathrm{NaCl}(\mathrm{D})$, respectively, in North Korean young adult refugees $(\circ, \mathrm{n}=21)$ and South Korean participants $(\bullet, \mathrm{n}=41) .{ }^{\star} p<0.05,{ }^{* *} p<0.01,{ }^{* * *} p<0.001$ (Student's t-test).

take is regularly observed. ${ }^{15)}$ Recent reports by North Korean refugees also indicate that vegetables seasoned only with salt and served as a side dish represent a major part of the diet in North Korea. ${ }^{16,17)}$ The data obtained for salt in this study show that the recognition threshold was significantly lower in North Korean refugees, reflecting the sociological context described above. However, all mean detection thresholds were significantly lower in North Korean refugees than in the South Korean participants. Although conflicting reports exist, it is generally accepted that factors contributing to taste sensitivity in healthy subjects include age, gender, body mass index, cigarette smoking, and alcohol consumption. Cigarette smoking was slightly higher among the South Korean participants compared with the North Korean refugees, but there was no significant difference between the two groups. One alternative hypothesis would be that long-term exposure to a monotonous diet caused by food shortages could be expected to increase taste sensitivity. This result is consistent with a previous study, which found that the most common food complaint among North Korean refugees is regarding stronger tastes in South Korea. ${ }^{18)}$

The findings documented in the present study indicate that a prolonged food deficit seems to have changed the taste sen- sitivity of healthy North Korean refugees. The altered taste sensitivity was most pronounced for sweet and salty tastes and lasted up to 3.5 years after the refugees left North Korea.

\section{Acknowledgments}

This work was supported by National Research Foundation of Korea (NRF) grants NRF-2017R1A2B2008527. The authors wish to thank producer Joong-kyung Yoon of Korean Broadcasting System (Mysteries of the Human Body) for carrying out this study. We would also like to thank Ms. Yu Jin Kim for preparing the sensory evaluation.

\section{ORCID}

Mee-Ra Rhyu https://orcid.org/0000-0002-1693-8330

\section{REFERENCES}

1) Chang NS, Hwang JY. Food shortage, nutritional deprivation, and reduced body size in North Korean defectors. Korean J Nutr 2000;33(5):540-7.

2) Ministry of Unification. Settlement support for North Korean defectors. [cited 2019 Mar 3]. Available from: URL: https://www. unikorea.go.kr/eng_unikorea/whatwedo/support/.

3) Lee EJ, Pei YQ, Kim EM. A survey of the adaptation and preference for South Korean food in North Korean refugees. Korean J Culin Res 2013;19(2):93-110.

4) Food and Agriculture Organization of the United Nations. Low-income food-deficit countries (LIFDCs)-list for 2018. [cited 2019 Mar 3]. Available from: URL: http://www.fao.org/countryprofiles/lifdc/en. 
5) Macdonald BA, Watts BM, Fitzpatrick DW. Comparison of taste thresholds in selected Canadian and Peruvian populations. Ecol Food Nutr 1993;30(3-4):241-51.

6) Jamel HA, Sheiham A, Cowell CR, Watt RG. Taste preference for sweetness in urban and rural populations in Iraq. J Dent Res 1996;75(11):1879-84.

7) Cho H, Kim SM, Jeong SS, Kim SB. Comparison of salt taste thresholds and salt usage behaviours between adults in Myanmar and Korea. Asia Pac J Clin Nutr 2016;25(4):879-84.

8) Pepino MY, Mennella JA. Effects of cigarette smoking and family history of alcoholism on sweet taste perception and food cravings in women. Alcohol Clin Exp Res 2007;31(11):1891-9.

9) Shepherd R. Sensory influences on salt, sugar and fat intake. Nutr Res Rev 1988;1(1):125-44.

10) Yamauchi Y, Endo S, Sakai F, Yoshimura I. A new whole-mouth gustatory test procedure. 1. Thresholds and principal components analysis in healthy men and women. Acta Otolaryngol Suppl 2002; 122(4):39-48.

11) Wise PM, Nattress L, Flammer LJ, Beauchamp GK. Reduced dietary intake of simple sugars alters perceived sweet taste intensity but not perceived pleasantness. Am J Clin Nutr 2016;103(1):50-60.

12) Mattes RD. The taste for salt in humans. Am J Clin Nutr 1997;65(2 Suppl):692S-7S.

13) Pangborn RM, Pecore SD. Taste perception of sodium chloride in relation to dietary intake of salt. Am J Clin Nutr 1982;35(3):510-20.

14) Wasalathanthri S, Hettiarachchi $P$, Prathapan $S$. Sweet taste sensitivity in pre-diabetics, diabetics and normoglycemic controls: a comparative cross sectional study. BMC Endocr Disord 2014;14:67.

15) Suh HD. Status of vegetable industry in North Korea. Korean J Hortic Sci Technol 2001;19(3):391-4.

16) MK. North Korean women 'shock testimony'. [online] 2013 Jan 11 [cited 2017 Aug 9]. Available from: URL: https:/www.mk.co.kr/ news/politics/view/2013/01/26563/.

17) Chosun.com. Why North Korea's food is more woven. [online] 2013 Jan 14 [cited 2017 Aug 9]. Available from: URL: http://news. chosun.com/site/data/html_dir/2013/01/13/2013011300465.html.

18) Lee EJ, Pei YQ. A study on the differences in dietary satisfaction with age in North Korean refugees. Korean J Food Cult 2012;27(6):636-45. 